\title{
HYPOTHESIS: THE MHC-RESTRICTED T-CELL RECEPTOR AS A STRUCTURE WITH TWO MULTISTATE ALLOSTERIC COMBINING SITES*
}

\author{
W. Louis Cleveland and Bernard F. ErLanger \\ Department of Microbiology, Columbia University Cancer Center/Institute of Cancer Research, \\ New York, NY 10032, U.S.A. \\ (Accepted 10 July 1984)
}

\begin{abstract}
This paper presents a dual-recognition model of the T-cell receptor that has been constructed to account for the phenomenon of MHC restriction as well as the paradoxical ability of T-cells to be both multispecific and precisely specific at the same time. In our model the combining sites for antigen and $\mathrm{MHC}$ are not independent as in classical dual-recognition models, but interact with each other by an allosteric mechanism. We envision a flexible receptor with combining sites for antigen and $\mathrm{MHC}$ that are capable of existing in a multitude of distinct complementarity states. MHC and antigen molecules act as allosteric effectors such that one ligand perturbs the conformation and therefore the specificity of the site for the other ligand. An essential feature of the model is that different MHC determinants induce different conformations at the anti-antigen site. In this way the receptor acquires multiple specificities. Within a particular complementarity state, precise recognition results from the requirement that antigen and $\mathrm{MHC}$ exhibit positive cooperativity in their binding to the T-cell receptor. Positive cooperativity is also the basis for MHC restriction. Reaction mechanisms are presented which describe the requirement that antigen and MHC both induce conformational changes in order to generate high-affinity binding to either ligand. As a precedent for the multistate allosteric receptor model, we discuss the properties of allosteric enzymes, especially ribonucleotide reductase, whose properties are analogous to those we have postulated for the T-cell receptor. Also discussed is the possibility that molecules such as Ly2, L3T4 and the Mls antigen, which have been found to play a role in antigen recognition, function as affinity-enhancing allosteric effectors that interact with the constant portion of the T-cell receptor.
\end{abstract}

\section{INTRODUCTION}

One of the most controversial issues in contemporary immunology is the nature of the $\mathrm{T}$-cell receptor for antigen. In spite of intensive investigations for more than a decade, the nature of the T-cell receptor remains obscure. Virtually all aspects of the problem have generated unresolved controversy. At the center of this controversy is the phenomenon of $\mathrm{MHC}$ restriction. In marked contrast to B-cells, major classes of T-cells do not functionally recognize isolated conventional antigen (A) molecules. Rather, A is only recognized in association with self MHC molecules (Kindred and Shreffler, 1972; Rosenthal and Shevach, 1973; Zinkernagel and Doherty, 1974a; Miller et al., 1975; Cohn and Epstein, 1977). Several ingenious theoretical models have been constructed to account for this phenomenon (Katz et al., 1973; Zinkernagel and Doherty, 1974a, b; Blanden et al., 1976c, 1980; Janeway et al., 1976, 1980a; Blanden and Ada, 1978; Langman, 1978; Cohn and Epstein, 1978; Benacerraf, 1978; Schrader, 1979; Williamson, 1980; Dröge, 1981; Eichmann, 1981; Reinherz et al., 1983; Swain et al., 1983). Most of these models fall into

* We dedicate this paper to Dr E. A. Kabat and to his first graduate student, the late Dr Sam M. Beiser, both of whom greatly influenced the course of research in this laboratory. This research was supported by NIH Grant AI-17949. two categories: single-recognition models which postulate the existence of neoepitopes that arise as a result of an interaction between $A$ and $\mathrm{MHC}$ molecules, and dual-recognition models which postulate the existence of separate receptors for $A$ and $\mathrm{MHC}$ molecules or else the existence of independent sites on a single receptor. While impressive data have been marshalled in support of both types of models, it is our view that none of the proposed theories are fully consistent with all of the data that can be considered to be well-established. We have therefore been led to reconsider the T-cell receptor problem in the context of $\mathrm{MHC}$ restriction. In this communication, we propose a new type of dual-recognition model which envisions a flexible receptor capable of assuming many different conformational states. We present this model in the hope that it may be useful in understanding the biochemical data that are beginning to emerge from the application of the recombinant DNA and monoclonal antibody technologies to the $\mathrm{T}$-cell receptor problem.

\section{PARADOXICAL ASPECTS OF T-CELL A SPECIFICITY}

The construction of this model has been carried out not only to account for MHC restriction but also to explain a paradoxical aspect of $\mathrm{T}$-cell antigen specificity. A number of studies have shown that MHC-restricted T-cells are capable of recognizing A-MHC combinations in an exquisitely specific 
fashion. In these studies, it was found that a change of one or two residues in the amino acid sequence of either A or MHC caused a loss of recognition (Keck, 1975; Zinkernagel, 1976; Maizels et al., 1980; Whitmore and Gooding, 1981; DeWaal et al., 1983; Townsend et al., 1983a, b; Berkower et al., 1984; Lin et al., 1984). Other studies have indicated that hapten-specific T-cells are also capable of recognizing subtle differences in hapten structures (Gell and Silverstein, 1962; Silverstein and Gell, 1962; Janeway et al., 1975, 1976a, b; Levy and Shearer, 1982; Rao et al., 1984).

Although some studies (Simpson et al., 1978; Nagy and Elliot, 1979; Janeway et al., 1982) have indicated that alloreactive T-cells are more crossreactive than self-MHC restricted T-cells, other studies (Melief et al., 1980; Sherman, 1982; DeWaal et al., 1983) with MHC mutants have suggested that this is due to the antigenic complexity of $\mathrm{MHC}$ molecules, rather than to a lack of specificity. In particular, studies at the clonal level have indicated that single amino acid substitutions can cause loss of recognition (Sherman, 1982). Thus, alloreactive Tcells are also capable of highly specific recognition of conformational nuances.

The aforementioned body of data which are based on studies of both populations and single clones of $T$-cells leads to the conclusion that $T$-cells are capable of recognizing antigen with great precision. There is, however, another growing body of data which give quite a different impression. A number of clones, initially selected for specificity to A + self MHC have also been found to possess alloreactivity, i.e. $\mathrm{A}+$ self $\mathrm{MHC}=$ allo MHC (Bevan, 1977; Billings et al., 1977; Burakoff et al., 1978; von Boehmer et al., 1979; Brachiale et al., 1981; Askonas and Lin, 1982; Guimezanes et al., 1982a, b; Hurtenbach et al., 1983; Abromson-Leeman and Cantor, 1983). In these cases, the MHC molecules differ by a large number of amino acids. $A$ is either eliminated or, as some have suggested (Matzinger and Bevan, 1977), replaced by some endogenous non-polymorphic A on the target cell that is likely to have a very different amino acid sequence. Thus recognition is preserved in spite of large changes in $\mathrm{A}$ and MHC. Taken in isolation, this body of data could be construed as evidence for a high degree of multispecificity and therefore a lack of precision in antigen recognition.

Another approach, based on limiting-dilution methods, has also produced data that point to a high degree of $T$-cell multispecificity. It has been found that precursor $\mathrm{T}$-cells specific for determinants on typical A (e.g. Strep. A, TNP and SRBC) occur at a frequency of about 1\% (Eichmann et al., 1982; Fey et al., 1983). Given the large diversity of As, this surprisingly high precursor frequency, which is substantially higher than B-cell precursor frequencies, implies a high degree of multispecificity in T-cell A recognition.
How is it possible that T-cells can be precisely specific and multispecific at the same time? Eichmann et al. (1982) have suggested that the apparent precision of $\mathrm{T}$-cell antigen recognition seen in some studies is not due to intrinsic properties of the T-cell receptor, but is rather a property of populations of $\mathrm{T}$-cells that arises as a result of regulation. This argument cannot be immediately excluded for earlier studies which assayed populations of cells. However, a substantial number of more recent studies which demonstrate precise recognition have employed T-cell clones. In these cases it is reasonable to assume that the observed specificity is a reflection of the intrinsic specificity of the $T$-cell receptor. It thus appears that the simultaneous juxtaposition of precise specificity and multispecificity is a genuine paradox that must be resolved.

Our approach to resolving this paradox is based on the findings of Hünig and Bevan $(1981,1982)$, who have isolated clones having a dual specificity of the form A1 + MHC1 = A2 + MHC2. Cold target inhibition studies have shown that a single receptor recognizes both $\mathrm{A}-\mathrm{MHC}$ combinations. If this dual specificity is interpreted in the context of a singlerecognition model, it becomes necessary to assume that the two A-MHC combinations generate neoepitopes that are cross-reactive relative to the single specificity of the receptor. Since little is currently known about the rules of neoepitope formation, it is difficult to pursue this line of interpretation further. However, if the dual specificity is interpreted in the context of a dual-recognition model, several important conclusions can be deduced. First, it might be expected that the dual specificity results from crossreactivity of $A 1$ and $A 2$ relative to the anti-A site and cross-reactivity of $\mathrm{MHC} 1$ and $\mathrm{MHC} 2$ relative to the anti-MHC site. Given the known multispecificity of T-cells it is conceivable that $\mathrm{A} 1$ or $\mathrm{A} 2$ could bind to the anti-A site in spite of a poor fit, or that the anti-A site contains distinct subsites that react with $A 1$ and A2. Similar expectations would also apply to the anti-MHC site. This explanation predicts that the cross-permutations $\mathrm{A} 1+\mathrm{MHC} 2$ and $\mathrm{A} 2+$ $\mathrm{MHC} 1$ should also be recognized. However, Hünig and Bevan $(1981,1982)$ have shown that they are not recognized. This rules out the "poor-fit" and "subsite" interpretations, and suggests that T-cell multispecificity cannot be equated with poor specificity.

The failure to recognize the cross-permutations also has additional implications for dual-recognition models. Classical dual-recognition models envision either separate anti-A and anti-MHC receptors or else independent sites on a single receptor. These models clearly predict that the cross-permutations described earlier should be recognized. That they are not seems to rule out these models. The firmness of this conclusion is further established by the findings of Kappler et al. (1981). Using hybrid Tcells having two distinct specificities (i.e. A1 + 
$\mathrm{MHC1} \neq \mathrm{A} 2+\mathrm{MHC2}$ ) they have also found that the cross-permutations are not recognized. In addition, Harris et al. (1984) have made similar observations with T-cells having hybrid membranes.

Given that classical dual-recognition models are ruled out, it might be concluded that available data are best explained with a single-recognition model. While single-recognition models are consistent with the data, it should be stressed that dual-recognition models with interacting sites, i.e. non-independent sites, are not ruled out.

In addition to being incompatible with the nonrecognition of the cross-permutations described earlier, classical dual-recognition models appear unable to provide a framework in which to resolve the apparently paradoxical juxtaposition of precise specificity and multispecificity. A tacit assumption of classical dual-recognition models is that $\mathrm{A}$ and MHC molecules interact with their binding sites according to "lock-and-key" principles. This is tantamount to assuming a rigid receptor (Koshland, 1958) and, in the context of a rigid receptor, it seems inevitable that multispecificity be equated with poor specificity. However, it appears that the paradoxical aspects of T-cell antigen specificity can be resolved in the context of a flexible receptor. By a flexible receptor, we mean a receptor which can exist in several different conformations that represent distinct complementarity states. The multispecificity of the T-cell receptor is explained by the existence of multiple complementarity states, while the finespecificity data are accommodated by assuming that, within a given complementarity state, antigen recognition is exquisitely specific. A flexible receptor is also required if the sites are to interact with and perturb each other. Otherwise, it would not be possible for the binding of a ligand at one site to alter the conformation of the other site. In what follows we attempt to show that a two-site receptor capable of assuming many conformational states that are allosterically controlled by $\mathrm{A}$ and MHC ligands is consistent with available data.

The construction of the multistate allosteric receptor model must accommodate four constraints:

(1) A recognition is MHC-restricted.

(2) A recognition is multispecific and precisely specific at the same time.

(3) Recognition at the anti-A site is not independent of recognition at the anti-MHC site.

(4) The combining sites of T-cell receptors contain variable regions which are expressed in a clonal fashion.

With these in mind, we present the following postulates.

\section{Postulate 1}

The T-cell receptor is an allosteric receptor that can simultaneously interact with two allosteric effector ligands: one ligand is a determinant on an MHC molecule and the other is a determinant on an A molecule.

We first consider interactions between the T-cell receptor and MHC molecules. Since the T-cell receptor has one or more variable regions, we refer to it in what follows as a "V-molecule". A basic requirement imposed by the phenomenon of MHC restriction is that T-cells (i.e. mature peripheral $\mathrm{T}$ cells) are not activated by recognition of self MHC. In other words, binary complexes between $\mathrm{V}$ molecules and self MHC molecules do not trigger Tcells. On the other hand, if MHC molecules are to be allosteric effectors of $\mathrm{V}$-molecules, it is necessary that $\mathrm{V}$-molecules have at least a moderate affinity for self MHC determinants. We are thus led to the following postulates.

Postulate $2 a$. For every V-molecule expressed by a T-cell clone, there exists a determinant on some self $\mathrm{MHC}$ molecule such that $\mathrm{V}+\mathrm{M} \underset{k_{2}}{\stackrel{k_{1}}{\rightleftharpoons}} \mathrm{V}: \mathrm{M}$, where $K_{t}$ $>k_{1} / k_{2}>K_{p}$ ( $\mathrm{MHC}=\mathrm{M}$ in equations). $K_{t}$ is assumed to be an affinity threshold, above which the T-cell will be triggered, and $K_{p}$ is an affinity threshold above which the allosteric effector can induce a significant conformational change in V. For convenience, we will speak of three ranges of affinity $(K)$ : low affinity, where $K<K_{p}$, moderate affinity, where $K_{p}<K<K_{t}$, and high affinity, where $K>K_{t}$. For simplicity, we neglect the fact that triggering probabilities will also depend on the concns of A, MHC and V-molecules (Matis et al., 1982, 1983).

Postulate $2 b$. MHC restriction is a binding-event phenomenon in which: (a) binary complexes of high affinity do not form with self $A$, self $\mathrm{MHC}$ or with non-self A molecules, and (b) high-affinity binding, i.e. functionally significant binding to non-self $A$ molecules, occurs only when a ternary $A: V: M$ complex forms.

\section{DESCRIPTION OF THE NOMENCLATURE FOR COMPLEMENTARITY STATES OF V-MOLECULES}

As specified in postulate $1, \mathrm{~A}$ and $\mathrm{MHC}$ molecules are allosteric effectors of V-molecules. It is thus necessary to describe the complementarity states of $\mathrm{V}$-molecules that can arise by interactions with $\mathrm{A}$ and $\mathrm{MHC}$ molecules. Since two ligands can simultaneously influence conformation allosterically (postulate 1), two indices are needed. Let $V_{o o}$ denote the complementarity state of $\mathrm{V}$ when it is unperturbed by either $\mathrm{MHC}$ or $\mathrm{A}$. Let $\mathrm{V}_{\text {om }}$ represent the complementarity state (an equilibrium conformational state) induced by interaction with a particular determinant on an MHC molecule, in the absence of binding to A. Similarly, we let $V_{a o}$ denote the complementarity state induced by a particular determinant on an A molecule, in the absence of binding to MHC. If these determinants 
fashion. In these studies, it was found that a change of one or two residues in the amino acid sequence of either A or MHC caused a loss of recognition (Keck, 1975; Zinkernagel, 1976; Maizels et al., 1980; Whitmore and Gooding, 1981; DeWaal et al., 1983; Townsend et al., 1983a, b; Berkower et al., 1984; Lin et al., 1984). Other studies have indicated that hapten-specific $\mathrm{T}$-cells are also capable of recognizing subtle differences in hapten structures (Gell and Silverstein, 1962; Silverstein and Gell, 1962; Janeway et al., 1975, 1976a, b; Levy and Shearer, 1982; Rao et al., 1984).

Although some studies (Simpson et al., 1978; Nagy and Elliot, 1979; Janeway et al., 1982) have indicated that alloreactive $\mathrm{T}$-cells are more crossreactive than self-MHC restricted T-cells, other studies (Melief et al., 1980; Sherman, 1982; DeWaal et al., 1983) with MHC mutants have suggested that this is due to the antigenic complexity of MHC molecules, rather than to a lack of specificity. In particular, studies at the clonal level have indicated that single amino acid substitutions can cause loss of recognition (Sherman, 1982). Thus, alloreactive Tcells are also capable of highly specific recognition of conformational nuances.

The aforementioned body of data which are based on studies of both populations and single clones of $T$-cells leads to the conclusion that $T$-cells are capable of recognizing antigen with great precision. There is, however, another growing body of data which give quite a different impression. A number of clones, initially selected for specificity to A + self MHC have also been found to possess alloreactivity, i.e. $\mathrm{A}+$ self $\mathrm{MHC}=$ allo $\mathrm{MHC}$ (Bevan, 1977; Billings et al., 1977; Burakoff et al., 1978; von Boehmer et al., 1979; Brachiale et al., 1981; Askonas and Lin, 1982; Guimezanes et al., 1982a, b; Hurtenbach et al., 1983; Abromson-Leeman and Cantor, 1983). In these cases, the MHC molecules differ by a large number of amino acids. $\mathrm{A}$ is either eliminated or, as some have suggested (Matzinger and Bevan, 1977), replaced by some endogenous non-polymorphic $\mathrm{A}$ on the target cell that is likely to have a very different amino acid sequence. Thus recognition is preserved in spite of large changes in $\mathrm{A}$ and MHC. Taken in isolation, this body of data could be construed as evidence for a high degree of multispecificity and therefore a lack of precision in antigen recognition.

Another approach, based on limiting-dilution metheds, has also produced data that point to a high degree of T-cell multispecificity. It has been found that precursor $T$-cells specific for determinants on typical A (e.g. Strep. A, TNP and SRBC) occur at a frequency of about 1\% (Eichmann et al., 1982; Fey et al., 1983). Given the large diversity of As, this surprisingly high precursor frequency, which is substantially higher than B-cell precursor frequencies, implies a high degree of multispecificity in T-cell A recognition.
How is it possible that T-cells can be precisely specific and-multispecific at the same time? Eichmann et al. (1982) have suggested that the apparent precision of T-cell antigen recognition seen in some studies is not due to intrinsic properties of the T-cell receptor, but is rather a property of populations of T-cells that arises as a result of regulation. This argument cannot be immediately excluded for earlier studies which assayed populations of cells. However, a substantial number of more recent studies which demonstrate precise recognition have employed T-cell clones. In these cases it is reasonable to assume that the observed specificity is a reflection of the intrinsic specificity of the T-cell receptor. It thus appears that the simultaneous juxtaposition of precise specificity and multispecificity is a genuine paradox that must be resolved.

Our approach to resolving this paradox is based on the findings of Hünig and Bevan $(1981,1982)$, who have isolated clones having a dual specificity of the form $\mathrm{A} 1+\mathrm{MHC1}=\mathrm{A} 2+\mathrm{MHC} 2$. Cold target inhibition studies have shown that a single receptor recognizes both $\mathrm{A}-\mathrm{MHC}$ combinations. If this dual specificity is interpreted in the context of a singlerecognition model, it becomes necessary to assume that the two A-MHC combinations generate neoepitopes that are cross-reactive relative to the single specificity of the receptor. Since little is currently known about the rules of neoepitope formation, it is difficult to pursue this line of interpretation further. However, if the dual specificity is interpreted in the context of a dual-recognition model, several important conclusions can be deduced. First, it might be expected that the dual specificity results from crossreactivity of $A 1$ and $A 2$ relative to the anti-A site and cross-reactivity of $\mathrm{MHC1}$ and $\mathrm{MHC} 2$ relative to the anti-MHC site. Given the known multispecificity of $\mathrm{T}$-cells it is conceivable that $\mathrm{A} 1$ or $\mathrm{A} 2$ could bind to the anti-A site in spite of a poor fit, or that the anti-A site contains distinct subsites that react with A1 and A2. Similar expectations would also apply to the anti-MHC site. This explanation predicts that the cross-permutations $\mathrm{A} 1+\mathrm{MHC} 2$ and $\mathrm{A} 2+$ MHC1 should also be recognized. However, Hünig and Bevan $(1981,1982)$ have shown that they are not recognized. This rules out the "poor-fit" and "subsite" interpretations, and suggests that T-cell multispecificity cannot be equated with poor specificity.

The failure to recognize the cross-permutations also has additional implications for dual-recognition models. Classical dual-recognition models envision either separate anti-A and anti-MHC receptors or else independert sites on a single receptor. These models clearly predict that the cross-permutations described earlier should be recognized. That they are not seems to rule out these models. The firmness of this conclusion is further established by the findings of Kappler et al. (1981). Using hybrid Tcells having two distinct specificities (i.e. A1 + 
simultaneously perturb the conformation of $\mathrm{V}$, we write the induced complementarity state as $V_{\text {am }}$, which is an equilibrium conformational state that exists when the high-affinity ternary complex $A: V_{a m}: M$ is formed.

We now consider the reaction pathways that can lead to the formation of the high-affinity ternary complex. Because of the low probability that $\mathrm{A}$ and MHC will collide simultaneously with $\mathrm{V}$, we assume that the formation of a ternary complex occurs in two steps, Either V first reacts with $\mathrm{MHC}$ and the binary complex thus formed reacts with $A$ (pathway 1 ), or $\mathrm{V}$ first reacts with $\mathrm{A}$ and the resulting binary complex then reacts with MHC (pathway 2). We write pathway 1 as follows:

$$
\begin{aligned}
& \mathrm{V}_{\mathrm{oo}}+\mathrm{M} \underset{k_{2}}{\stackrel{k_{1}}{\rightleftharpoons}} \mathrm{V}_{\text {om }}: \mathrm{M} \text {, such that } \\
& K_{p}<k_{1} / k_{2}<K_{t} \\
& \mathrm{~A}+\mathrm{V}_{\mathrm{om}}: \mathrm{M} \underset{k_{4}}{\stackrel{k_{3}}{\rightleftharpoons}} \mathrm{A}: \mathrm{V}_{\mathrm{om}}: \mathrm{M}, \text { such that } \\
& K_{p}<k_{3} / k_{4}<K_{\iota} \\
& \mathrm{A}: \mathrm{V}_{\mathrm{om}}: \mathrm{M} \underset{k_{6}}{\stackrel{k_{5}}{\rightleftharpoons}} \mathrm{A}: \mathrm{V}_{\mathrm{am}}: \mathrm{M} \text {, such that } k_{5} / k_{6}>K_{t}
\end{aligned}
$$

This pathway requires that $\mathrm{V}_{\mathrm{om}}: \mathrm{M}$ have moderate affinity for $\mathrm{A}$. It is neither required nor excluded that $\mathrm{V}_{\mathrm{oo}}$ have moderate affinity for $\mathrm{A}$.

Pathway 2 can be written as follows:

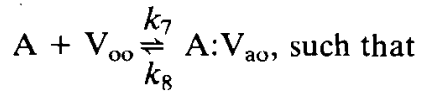

$$
\begin{aligned}
& K_{p}<k_{7} / k_{8}<K_{t}, \\
& \mathrm{~A}: \mathrm{V}_{\mathrm{ao}}+\mathrm{M} \underset{k_{10}}{\stackrel{k_{9}}{\rightleftharpoons}} \mathrm{A}: \mathrm{V}_{\mathrm{ao}}: \mathrm{M} \text {, such that } \\
& K_{p}<k_{9} / k_{10}<K_{t} \text {, } \\
& \mathrm{A}: \mathrm{V}_{\mathrm{ao}}: \mathrm{M} \underset{\hat{k}_{12}}{\stackrel{k_{11}}{\vec{k}}} \mathrm{~A}: \mathrm{V}_{\mathrm{am}}: \mathrm{M} \text {, such that } \\
& k_{11} / k_{12}>K_{t} \text {. }
\end{aligned}
$$

The requirements for pathway 2 are analogous to those of pathway 1 .

Both pathways involve two conformational changes, one induced by $\mathrm{A}$ and the other induced by $\mathrm{MHC}$, as required by postulate 2 which specifies that functional recognition of $A$ requires the formation of a high-affinity ternary complex.

\section{COOPERATIVITY AS THE BASIS FOR FINE SPECIFICITY}

At this point we are in a position to discuss the role of cooperativity in the binding of $\mathrm{A}$ and $\mathrm{MHC}$ molecules to $\mathrm{V}$-molecules. Consider pathway 1:
MHC binds to $\mathrm{V}$ and generates an intermediate complementarity state which has moderate affinity for $\mathrm{A}$. The binding of $\mathrm{A}$ to the intermediate complex is assumed to induce a second conformational change. This conformational change can affect the affinity of $\mathrm{V}$ for $\mathrm{MHC}$ in three possible ways: (1) the affinity for MHC is not significantly changed, (2) the affinity for $\mathrm{MHC}$ is reduced (negative cooperativity), or (3) the affinity for $\mathrm{MHC}$ is increased (positive cooperativity). These possibilities point to the requirement of positive cooperativity as a basis for explaining the exquisite specificity of $\mathrm{T}$-cell antigen recognition. Conceivably, there could exist a number of A determinants which might bind to the intermediate complex with moderate affinity. Only those determinants which induce a conformational change which increases the binding of $\mathrm{V}$ to both MHC and A will lead to a high-affinity ternary complex which is capable of triggering the cell. Equation (3) describes this type of conformational change. It is clear that the requirement for positive cooperativity in the binding of $\mathrm{A}$ and $\mathrm{MHC}$ to $\mathrm{V}$ is a device which increases specificity. We suggest that positive cooperativity is the basis for the exquisite specificity of T-cell antigen recognition.

\section{COOPERATIVITY AS BASIS FOR MHC RESTRICTION}

Positive cooperativity is also important in another context. A basic assumption in the construction of this model is the notion that MHC restriction is a binding-event phenomenon. This assumption is based on experiments in which $\mathrm{T}$-cells have been found to adhere to monolayers of target cells only when the target cells bear the correct A-MHC combination. Target cells without A molecules do not elicit adherence of A-specific T-cells. Blanden et al. (1980) have proposed a two-state dual-recognition model which invokes cooperative binding as a basis for explaining this phenomenon. Their model envisions two states in the T-cell receptor, a free state and an antigen-binding state. In the free state the anti-MHC site has a sufficiently low affinity to avoid adherence, while cooperative binding leads to an increase in affinity which causes adherence in the presence of A. In our view this model is inconsistent with the Hünig-Bevan phenomenon since it postulates only a single A-binding state. However, in the context of our multistate allosteric receptor model, positive cooperativity can still be invoked to account for A-dependent adherence of T-cells to targets.

AN EXPLANATION OF T-CELL MULTISPECIFICITY IN THE CONTEXT OF AN ALLOSTERIC T.CELL RECEPTOR

When interpreted in terms of a dual-recognition model, the data of Hünig and Bevan (A1 + self $\mathrm{MHC1}=\mathrm{A} 2+$ allo $\mathrm{MHC} 2$ ) suggest that a single $\mathrm{V}$ molecule can have different anti-A specificities when it is perturbed by different MHC molecules. 
We propose that this finding is an example of a general principle of multispecificity that applies to A recognition by $\mathrm{MHC}$-restricted $\mathrm{T}$-cells under physiological conditions. In particular, we propose that, within an organism, MHC determinants can be grouped into families of variant determinants such that, within a family, the variants are cross-reactive at the level of binary complexes but are sufficiently different in structure to differentially perturb the Vmolecules with which they form binary complexes. These different perturbations lead to different antiA specificities, thus accounting for the apparent multispecificity of $T$ cells. This explanation of multispecificity requires that $\mathrm{V}$-molecules possess multiple complementarity states and that MHC molecule determinants can be grouped into families of cross-reactive variants.

\section{POSSIBLE ORIGINS OF MHC DETERMINANT FAMILIES}

The well-known polymorphism of MHC loci generates a diversity of MHC molecules within the species. However, within a single organism, MHCencoded molecules that function as restriction elements appear to be homogeneous at the level of amino acid sequence (Steinmetz and Hood, 1983). It is therefore necessary to rationalize the existence of families of structurally different MHC determinants in an individual as specified earlier. We consider that $\mathrm{MHC}$ determinant families can arise in four ways.

\section{(1) Carbohydrate microheterogeneity}

Evidence exists that a protein conformation on a human MHC molecule, as recognized by a monoclonal antibody, is greatly perturbed by removal of carbohydrate side chains (Wilson et al., 1981). Moreover, tunicamycin treatment of virally infected target cells led to a $50 \%$ reduction of virus-specific CTL killing (Black et al., 1981). In another study (Gilmer et al., 1984), a wheat germ agglutinin resistant variant of the EL-4 cell line was found to have unsialyated $\mathrm{H}-2 \mathrm{~K}$ molecules. The fact that this variant would no longer grow in the peritoneal cavity of a syngeneic mouse suggested that absence of sialic acid made some determinants of the $\mathrm{H}-2 \mathrm{~K}$ molecule appear foreign to syngeneic T-cells. Microheterogeneity in the carbohydrate chains could generate a heterogeneity of perturbations, creating determinants that are variants of each other. Conceivably, the variant determinants would be sufficiently different to generate different $\mathrm{V}_{\text {om }}: \mathrm{M}$ intermediate states leading to different functional specificities for A molecules. Evidence for the existence of carbohydrate microheterogeneity in Class II MHC molecules has been presented by at least two different laboratories (Freed and Nathenson, 1977; Quill. and Schwartz, 1984).
(2) Internal-sequence homology in MHC molecules

Recently, Ohno et al. (1982) have shown that Class I MHC molecules contain internal-sequence homology. In particular, comparison of amino acid sequences of the first three domains indicates that the second and first (amino terminal) domains are progressively diversified copies of the third domain, which is the most conserved one. Since these domains are approximate copies of each other, it is reasonable to expect that some determinants in one domain may be sufficiently similar to corresponding determinants in another domain to be cross-reactive at the level of binary V:M complexes. Conceivably, the Class. II MHC molecules which function as restriction elements also possess similar internalsequence homology.

(3) Cross-reaction among different Class I restricting elements and among different Class II restricting elements

Hünig and Bevan have shown that a single clone can recognize two different A-MHC pairs, in which one MHC molecule is self and the other is allo. MHC molecules from two different haplotypes typically possess about $80 \%$ sequence homology in the domains thought to be recognized by T-cells (Steinmetz and Hood, 1983). Since H-2K and H-2D within a single haplotype possess similar sequence homology, we might expect that a particular clone could recognize one antigen in association with $\mathrm{H}$ $2 \mathrm{~K}$, another in association with $\mathrm{H}-2 \mathrm{D}$, and possibly a third antigen in association with $\mathrm{H}-2 \mathrm{~L}$, when it is present. Since these molecules have been shown to be cross-reactive at a serological level (Murphy and Shreffler, 1975) it is not unreasonable that they be cross-reactive as allosteric effectors at the level of binary complexes. Similar arguments might also apply to Class II restricting elements, since I-A and I-E molecules have been observed to cross-react at the level of alloreactive T-cells (Vucak et al., 1982).

In $F_{1}$-animals, the occurrence of cross-reactions (binary level) among determinants on MHC molecules of different haplotypes is also a possibility. That such cross-reactions can occur is supported by the findings of Hünig and Bevan ( $1+$ self $\mathrm{MHC}=$ $\mathrm{A} 2$ + allo MHC) and by the phenomenon of "aberrant recognition" in which normal splenic or thymic T-cells rigorously depleted of alloreactive cells are found to recognize conventional antigens in the context of allo MHC (Wilson et al., 1977; Doherty and Bennick, 1979; Stockinger et al., 1981).

\section{(4) Allostery of MHC molecules}

A tacit assumption underlying the discussion thus far is that the $A$ and $M H C$ molecules are rigid structures which have conformations that are preserved when they interact with $\mathrm{V}$-molecules. Given 
the enormous diversity of A molecules, exceptions to this assumption may exist but it is unlikely that they will be a typical occurrence. However, in the case of MHC molecules, there is recent evidence that multiple conformations may be a regular feature of these molecules. First, sequence data show that the Class I $\alpha_{1}$-domain and the Class II $\alpha_{1^{-}}$ and $\beta_{1}$-domains lack intradomain disulfide bonds, suggesting that these domains may possess flexibility. Secondly, pairs of monoclonal antibodies have been isolated which mutually enhance binding. This has been found for both Class I and Class II MHC molecules, using Fab fragments in some cases (Diamond et al., 1984; Lemmonier et al., 1984, and references therein). These findings have been interpreted as evidence of conformational flexibility. This raises the possibility that interactions between $\mathrm{V}$ and MHC may lead not only to conformational changes in $\mathrm{V}$-molecules but also to conformational changes in MHC molecules. The different conformations of MHC molecules should generate sets of cross-reactive variant determinants. In the event that families of MHC determinants are generated in this fashion, the reaction mechanisms described previously would have to be modified to include conformational changes in MHC molecules, but the basic steps in the two pathways would be essentially as described. If transitions between conformational states in MHC molecules play a role in T-cell antigen recognition, then it should be possible to find anti-MHC antibodies that enhance A-recognition. Very recently, monoclonal anti-HLA-DR antibodies that enhance the proliferative responses of A-specific T-cell clones have been described (Triebel et al., 1984).

\section{PRECEDENTS FOR MULTIPLE COMPLEMENTARITY STATES}

Our proposal that the T-cell receptor can assume multiple conformational states with multiple specificities has precedent in the field of enzymology. Of special interest in this connection are allosteric enzymes. Such enzymes fail to obey the MichaelisMenten kinetics that is predicted by a "lock-andkey" model (Koshland, 1958) and their behavior has been interpreted in terms of models which assume that these enzymes are capable of existing in multiple conformational states and that transitions between states occur as a result of interactions with ligands. Detailed theoretical models have been proposed [reviewed by Koshland and Neet (1968)].

An example of a well-studied multistate enzyme is ribonucleotide reductase from $E$. coli. It has been found that allosteric effectors can bind at four sites (Thelander and Reichard, 1979). Two identical sites control the overall activity; two other identical sites control specificity for substrate. Of special interest is the fact that the latter two sites can be occupied by four different effectors. Moreover, the specificity of the enzyme for the four different substrates (CDP, UDP, GDP and ADP) depends, in a parametric fashion, on the nature of effector ligands. That is, different effectors generate different specificities. These different specificities correspond to functionally distinct enzymes in the sense that $K_{m}$ and $K_{\text {cat }}$ are changed as a result of interaction with an effector. While only four states (three positive and one negative) appear to be physiologically relevant, Reichard and coworkers point out that the multiplicity of effectors and effector binding sites makes possible in vitro a large number of different states of the enzyme with different substrate specificities. This enzyme is thus a precedent for the multistate allosteric receptor model we have proposed. The combining site of the enzyme can exist in a multitude of conformational states and these states can be selected by changing the effector ligand binding at the specificity sites. These features are directly analogous to what we have proposed for the T-cell antigen receptor.

THE MULTISTATE ALLOSTERIC RECEPTOR MODEL AND THE ROLE OF THE Ly2, L3T4 AND MIs MOLECULES IN ANTIGEN RECOGNITION

Recent studies have shown that the Ly2 and L3T4 molecules play a role in antigen recognition by $\mathrm{T}$ cells (Nakayama et al., 1979; Shinohara and Sachs, 1979; Swain et al., 1984). In the case of the Ly2 molecule, available data suggest that this molecule enhances the affinity of antigen binding, being essential when the $T$-cell receptor has a borderline affinity for antigen, but not when the receptor has an intrinsically high affinity. This picture has emerged from studies in which anti-Ly2 antibodies have been shown to inhibit target cell binding of some but not all clones (MacDonald et al., 1982). We take these findings as evidence for the possible existence of a third allosteric site on the Class I restricted $\mathrm{T}$-cell receptor which can bind Ly2. On the basis of the low polymorphism of the Ly2 antigen, we expect the binding site for Ly2 to have an invariant amino acid sequence and therefore to be in the constant region of the receptor molecule. In analogy with the interaction of $\mathrm{Clq}$ and immunoglobulin, we further expect that the formation of an antigen-T-cell receptor complex will create a perturbed Ly2 binding site that binds Ly2 with increased affinity, leading to a more stable complex.

In the case of murine Class II restricted T-cells, the L3T4 antigen may be analogous to the Ly2 antigen since a monoclonal anti-L3T4 antibody has been found to inhibit antigen binding but to different degrees with different clones (Swain et al., 1984).

Another interesting possibility is that the Mls antigen (Festenstein, 1973), present on B-cells and macrophages, may also function as an affinity enhancing allosteric effector of Class II restricted T- 
cells. The fact that allotypic forms of the Mls antigen can stimulate an even greater fraction of precursors than the MHC antigen of a foreign haptotype (Janeway et al., 1980; Lutz et al., 1981) is consistent with the possibility that all Class II restricted T-cell receptors have an anti-Mls site. In the syngeneic case, we expect that the Mls antigen will have a subthreshold affinity for $\mathrm{V}_{\mathrm{oo}}$ (Molnar-Kimber and Sprent, 1983) or $\mathrm{V}_{\mathrm{om}}: \mathrm{M}$ (Jones and Janeway, 1982). The formation of the complete $A: V_{a m}: M$ complex is expected to create a perturbed Mls-binding site which will recognize the Mls antigen with functionally significant affinity, leading to stabilization of the complex as a whole.

Another molecule of low polymorphism, which may function as an allosteric effector of the T-cell receptor is the T3 antigen. This antigen is found on all human T-cells and appears to be associated with clonotypic structures (Reinherz et al., 1983).

\section{ASYMMETRIC ANTIBODY INHIBITION OF T-CELL} A RECOGNITION: INTERPRETATION IN THE CONTEXT OF THE MULTISTATE ALLOSTERIC RECEPTOR MODEL

One of the more puzzling aspects of MHCrestricted T-cell A recognition is the differential ability of anti-A and anti-MHC antibodies to inhibit $\mathrm{A}$ recognition. In general, anti- $\mathrm{A}$ antibodies have been found to be weak inhibitors, whereas inhibition with anti-MHC antibodies has been easily achieved. This has been found for both Class I and Class II restricted T-cells (Askonas and Webster, 1980; Finberg and Benacerraf, 1981; Zinkernagel and Rosenthal, 1981). A possible explanation of this phenomenon in the context of the multistate allosteric receptor model can be derived from an inspection of the reaction pathways that can lead to formation of the high-affinity ternary complex (discussed earlier). Antibodies could inhibit T-cell recognition by competing with the high-affinity $A: V: M$ complex or by preventing the formation of the binary $A: V$ or $V: M$ complexes, which are of only moderate affinity. If the $A: V: M$ complex is of sufficiently high affinity to make direct antibody competition unlikely, then antibody inhibition would have to occur by inhibiting formation of binary complexes. For pathway 1, only anti-MHC antibodies would be effective, and, for pathway 2 , only anti-A antibodies would be effective. That only anti-MHC antibodies are efficient inhibitors is consistent with the possibility that only pathway 1 leads to the formation of high-affinity ternary complexes.

\section{CONCLUSION}

The remarkable findings of Hünig and Bevan, Kappler, Harris, and their respective coworkers, have led to the conclusion that dual-recognition models with independent anti- $\mathrm{A}$ and anti-MHC sites are untenable. This has in turn led to the view, by others, that single-recognition or altered-self models are the remaining viable alternative. We have tried to demonstrate that dual-recognition models with interacting anti-A and anti-MHC sites can be consistent with these findings. The notion that the sites interact with each other leads naturally to an allosteric receptor model. We further demonstrate that paradoxical aspects of $T$-cell antigen specificity as well as the phenomenon of $\mathrm{MHC}$ restriction can be accommodated in the context of a multistate allosteric receptor model that has as precedents certain findings established for allosteric enzymes.

\section{REFERENCES}

Abromson-Leeman S. R. and Cantor H. S. (1983) Specificity of T-cell clones for antigen and autologous major histocompatibility complex products determines specificity for foreign major histocompatibility complex products. J. exp. Med. 158, 428-437.

Alkan S. S. and El-Khateeb M. (1975) Comparison of specificities of humoral and cellular immune responses to haptens. Eur. J. Immun. 5, 766-770.

Askonas B. A. and Lin Y. L. (1982) An influenza specific T-killer clone is restricted to $\mathrm{H}-2 \mathrm{~L}^{\mathrm{d}}$ and cross-reacts with $\mathrm{D}^{\mathrm{k}}$ region. Immunogenetics $16,83-87$.

Askonas B. A. and Webster R. G. (1980) Monoclonal antibodies to hemagglutinin and to $\mathrm{H}-2$ inhibit the crossreactive cytotoxic T-cell populations induced by influenza. Eur. J. Immun. 10, 151-156.

Barcinski M. A. and Rosenthal A. S. (1977) Immune response gene control of determinant selection: I. Intramolecular mapping of the immunogenic sites on insulin recognized by guinea pig $\mathrm{T}$ and B cells. J. exp. Med. 145, 726-742.

Beck R. N., Frelinger J. G., Shigeta M., Infante A. J., Cummings D., Hammerling G. and Fathman G. C. (1982) T-cell clones specific for hybrid I-A molecules: discrimination with monoclonal anti-I-A ${ }^{\mathrm{k}}$ antibodies. $J$. exp. Med. 156, 1186-1194.

Benacerraf B. (1978) Opinion: a hypothesis to relate the specificity of T'lymphocytes and the activity of I-region specific Ir genes in macrophages and B-lymphocytes. $J$. Immun. 120, 1809-1812.

Berkower I., Matis L., Buckenmeyer G. K., Gurd F. R. N., Longo D. L. and Berzofsky J. A. (1984) Identification of distinct predominant epitopes recognized by myoglobin-specific T-cells under the control of different Ir genes and characterization of representative T-cell clones. J. Immun. 132, 1370-1378.

Bevan M. J. (1977) Killer cells reactive to altered-self antigens can also be alloreactive, Proc. natn. Acad. Sci. U.S.A. 74, 2094-2098.

Billings P., Burakoff S., Dorf M. E. and Benacerraf B. (1977) Cytotoxic T-lymphocytes induced against allogeneic I-region determinants react with Ia molecules on trinitrophenyl-conjugated syngeneic target cells. $J$. exp. Med. 146, 623-628.

Black P. L., Vitetta E. S., Forman, J., Kang C.-Y., May R. D. and Uhr J. W. (1981) Role of glycosylation in the H-2-restricted cytolysis of virus-infected cells. Eur. J. Immun. 11, 48-55.

Blanden R. V. and Ada G. L. (1978) A dual recognition model for cytotoxic T-cells based on thymic selection of precursors with low affinity for self $\mathrm{H}-2$ antigens. Scand. J. Immun. 7, 181-190.

Blanden R. V., Dunlop M. B. C., Doherty P. C., Kohn I. and McKenzie I. F. C. (1976a) Effects of four H-2K 
mutations on virus-induced antigens recognized by cytotoxic T-cells. Immunogenetics 3, 541-590.

Blanden R. V., Gill D. B. E. C., Zidovetzki R. and Pecht I. (1980) Cooperativity in antigen binding as a potential element in Tc cell recognition. Molec. Immun. 17, 893-896.

Blanden R. V., Hapel A. J., Doherty P. C. and Zinkernagel R. M. (1976b) Lymphocyte-macrophage interactions and macrophage activation in the expression of antimicrobial immunity in vivo. In Immunobiology of the Macrophage (Edited by Nelson D. S.), pp. 367-400. Academic Press, New York.

Blanden R. V., Hapel A. J. and Jackson D. C. (1976c) Mode of action of Ir genes and the nature of T-cell receptors for antigen. Immunochemistry 13, 179-191.

Brachiale T. J. (1977) Immunologic recognition of influenza virus-infected cells. I. Generation of a virusstrain specific and a cross-reactive subpopulation of cytotoxic T-cells in the response to type A influenza viruses of different subtypes. Cell. Immun. 33, 423-436.

Brachiale T. J., Andrew M. E. and Brachiale V. L. (1981) Simultaneous expression of $\mathrm{H}-2$ restricted and alloreactive recognition by a cloned line of influenza virusspecific cytotoxic T-lymphocytes. J. exp. Med. 153, 1371-1376.

Burakoff S. J., Feinberg R., Glimcher L., Lemmonier F., Benacerraf B. and Cantor H. (1978) The biologic significance of alloreactivity. The ontogeny of T-cell sets specific for alloantigens or modified self antigens. J. exp. Med. 148, 1414-1422.

Cohn M. and Epstein R. (1977) Characterization of an inhibitory allogeneic effect on humoral responsiveness in vitro. Scand. J. Immun. 6, 39-58.

Cohn M. and Epstein R. (1978) T-cell inhibition of humoral responsiveness: II. Theory on the role of restrictive recognition in immune regulation. Cell. Immun. 39, 125-153.

DeWaal, L. P., Melvold R. W. and Melief C. J. M. (1983a) Cytotoxic T-lymphocyte nonresponsiveness to the male antigen $\mathrm{H}-\mathrm{Y}$ in the $\mathrm{H}-2^{\mathrm{b}}$ mutants bm 13 and bm 14. J. exp. Med. 158, 1537-1546.

DeWaal L. P., Nathenson S. G. and Melief C. J. M. (1983b) Direct demonstration that cytotoxic lymphocytes recognize conformational determinants and not primary amino acid sequences. $J$. exp. Med. 158, 1720-1726.

Diamond A. G., Butcher G. W. and Howard J. C. (1984) Localized conformational changes induced in a Class I major histocompatibility antigen induced by the binding of monoclonal antibodies. J. Immun. 132, 1169-1175.

Doherty P. C. and Bennick J. R. (1979) Vaccinia-specific cytotoxic $\mathrm{T}$-cell responses in the context of $\mathrm{H}-2$ antigens not encountered in thymus may reflect aberrant recognition of a virus-H-2 complex. J. exp. Med. 149, $150-157$

Doherty P. C., Blanden R. V. and Zinkernagel R. M. (1976) Specificity of virus-immune effector T-cells for $\mathrm{H}$ 2K or H-2D compatible interactions: implications for $\mathrm{H}$ antigen diversity. Transplantn Rev. 29, 89-124.

Dröge W. (1981) Theoretical considerations and probability models for the somatic development of the T-cell repertoire. Cell. Immun. 57, 251-264.

Eichmann K. (1981) A three-site interaction model for antigen specificity, MHC-restriction, and Ir gene control in lymphocyte communication. Immunobiology 158, 145-150.

Eichmann K., Goronzy J., Hamann U., Krammer P. H. Kuppers R. C., Melchers I., Simon M. M. and Zahn G. (1982) Clonal analysis of helper and cytolytic T-cells: multiple, independently regulated precursor sets at frequencies suggesting a limited repertoire. In Isolation, Characterization and Utilization of T-lymphocyte Clones (Edited by Fathman C. G. and Fitch F. W.), pp. 234-244. Academic Press, New York.
Festenstein H. (1973) Immunogenetic and biological aspects of in vitro lymphocyte allotransformation (MLR) in the mouse. Transplantn Rev. 15, 62-88.

Fey K., Melchers I. and Eichmann K. (1983) Quantitative studies on T-cell diversity: IV. Mathematical analysis of multiple limiting populations of effector and suppressor T-cells. J. exp. Med. 158, 40-52.

Finberg R. and Benacerraf B, (1981) Induction, control and consequences of virus-specific cytotoxic T-cells. Immun. Rev. 58, 157-180.

Freed J. H. and Nathenson S. G. (1977) Similarity of the carbohydrate structures of $\mathrm{H}-2$ and Ia glycoproteins. $J$. Immun. 119, 477-482.

Gell P. G. H. and Silverstein A. M. (1962) Delayed type hypersensitivity to hapten-protein conjugates. I. The effect of carrier protein and site of attachment to hapten. J. exp. Med. 115, 1037-1051.

Gilmer P. J., Figard S. D. and Flores R. V. (1984) Wheat germ agglutinin-resistant variant of EL-4 containing altered oligosaccharides as a target cell for cytotoxic $\mathrm{T}$ cells. Cell. Immun. 83, 107-123.

Guimezanes A., Albert F. and Schmitt-Verhulst A.-M. (1982a) I region-restricted T-cell line stimulated with hapten-treated syngeneic cells: selection of clones with reactivity for both allogeneic la determinants and self IA plus hapten. Eur. J. Immun. 12, 195-199.

Guimezanes A., Davignon J.-L. and Schmitt-Verhulst A. M. (1982b) Multiple cytolytic T-cell clones with distinct cross-reactivity patterns coexist in anti-self + hapten cell lines. Immunogenetics 16, 37-46.

Harris D. T., MacDonald H. R. and Cerottini J.-C. (1984) Antigen recognition by $\mathrm{H}-2$ restricted cytolytic $\mathrm{T}$ lymphocytes is not mediated by two independent receptors. J. exp. Med. 159, 330-335.

Hünig T. R. and Bevan M. J. (1981) Specificity of T-cell clones illustrates altered self hypothesis. Nature, Lond. 294, 460-462.

Hünig T. R. and Bevan M. J. (1982) Antigen recognition by cloned cytotoxic $\mathrm{T}$-lymphocytes follow rules predicted by the altered self hypothesis. $J$. exp. Med. 155, $111-125$.

Hurtenbach U., Shearer G. M. and Levy R. B. (1983) Cross-reactive recognition of alloantigens and certain $B 6$ mutant antigens by antigen-specific and polyclonally activated cytotoxic effector cells. Cell. Immun. 80 , $163-171$.

Janeway C. A., Jr, Cohen B. E., Ben-Sasson S. Z. and Paul W. E. (1975) The specificity of cellular immune responses in guinea pigs. I. T-cells specific for 2,4dinitrophenyl-D-tyrosyl residues. $J$. exp. Med. 141, 42-55.

Janeway C. A., Jr, Jones B., Binz H., Frischknecht H. and Wigzell H. (1980a) T-cell receptor idiotypes. Scand. J. Immun. 12, 83-92.

Janeway C. A., Jr, Lerner E. A., Conrad P. J. and Jones B. (1982) The precision of self and non-self major histocompatibility complex encoded antigen recognition by cloned T-cells. Behring Inst. Mitt. 70, 200-209.

Janeway C. A., Jr, Lerner E. A., Jason J. M. and Jones B. (1980b) T-lymphocytes responding to Mls-locus antigens are $\mathrm{Lyt}_{-1}^{+}, 2^{-}$and I-A restricted. Immunogenetics 10, 481-497.

Janeway C. A., Jr, Maurer P. H., Dailey M. D. and Inman J. K. (1976) The specificity of cellular immune responses in guinea pigs. II. The structure of antigenic determinants leading to T-lymphocyte stimulation. $J$. exp. Med. 144, 1621-1640.

Janeway C. A., Jr and Paul W. E. (1976) The specificity of cellular immune responses in guinea pigs. III. The precision of antigen recognition by T-lymphocytes. $J$. exp. Med. 144, 1641-1656.

Jones B. and Janeway C. A., Jr (1982) MHC recognition by clones of Mls specific T-lymphocytes. Immuno- 
genetics 16, 243-255.

Kappler J. W., Skidmore B., White J, and Marrack P. (1981) Antigen-inducible, H-2-restricted interleukin-2producing T-cell hybridomas. $J$. exp. Med. 153, 11981214.

Katz D. H., Hamaoka T., Dorf M. E. and Benacerraf B. (1973) Cell interactions between histoincompatible $T$ and $\mathrm{B}$ lymphocytes. The $\mathrm{H}-2$ gene complex determines successful physiologic lymphocyte interactions. Proc. natn. Acad. Sci. U.S.A. 70, 2624-2628.

Keck K. (1975) Ir gene control of immunogenicity of insulin and A chain loop as a carrier determinant. Nature, Lond. 254, 78.

Kindred B. and Shreffler D. C. (1972) H-2 dependence of cooperation between $\mathrm{T}$ and $\mathrm{B}$ cells in vivo. J. Immun. 109, 940-943.

Koshland D. E., Jr (1958) Application of a theory of enzyme specificity to protein synthesis. Proc. natn. Acad. Sci. U.S.A. 44, 98-104.

Koshland D. E., Jr and Neet K. E. (1968) The catalytic and regulatory properties of enzymes. A. Rev. Biochem. $37,359-410$.

Langman R. E. (1978) Cell-mediated immunity and the major histocompatibility complex. Rev. Physiol. Biochem. Pharmac. 81, 1-37.

Lemmonier F. A., LeBouteiller P. P., Olive D., Malissen B., Mishal Z., Layet C., Dubreuil J., Caillol D. H., Kourilsky F. M. and Jordan B. R. (1984) Transformation of LMTK $^{-}$cells with purified Class I genes V. Antibody-induced structural modification of HLA Class I molecules results in potentiation of the fixation of a second monoclonal antibody. J. Immun. 132, 11761182.

Levy R. B. and Shearer G. M. (1982) Cell-mediated lympholysis responses against autologous cells modified with haptenic sulfhydryl reagents. J. Immun. 129 1525-1529.

Lin C.-C. S., Hansen T. H., Passmore H. C., Rosenthal A. S., Tse H. Y., Walsh W. D. and Kanamori S. (1984) Delineation of Ia: nominal antigen complementary determinants recognized by $T$-cells in studies of gene complementation in response to insulin. J. Immun. 132 303-309.

Lutz C. T., Glasebrook A. L. and Fitch F. W. (1981) Enumeration of alloreactive helper T-lymphocytes which cooperate with cytolytic T-lymphocytes. Eur. J. Immun. 11, 726-734.

MacDonald H. R., Glasebrook A. L. and Cerottini J.-C. (1982) Clonal heterogeneity in the functional requirement for Lyt $2 / 3$ molecules on cytolytic T-lymphocytes. Analysis by antibody blocking and selective trypsinization. J. exp. Med. 156, 1711-1722.

Maizels R. M., Clarke J. A., Harvey M. A., Miller A. and Sercarz E. E. (1980) Epitope specificity of the T-cell proliferative response to lysozyme: proliferative T-cells react predominantly to different determinants from those recognized by B-cells. Eur. J. Immun. 10, 509515.

Matis L. A., Jones P. P., Murphy D. B., Hedrick S. M. Lerner E. A., Janeway C. A., Jr, McNicholas J. M. and Schwartz R. H. (1982) Immune response gene function correlates with the expression of an Ia antigen. II. A quantitative deficiency in $\mathrm{Ae}: \mathrm{E}_{\alpha}$ complex expression. $J$. exp. Med. 155, 508-523.

Matis L. A., Glimcher L. H., Paul W. E. and Schwartz R. H. (1983) Magnitude of response of histocompatibility-restricted T-cell clones is a function of the product of the concentrations of antigen and Ia molecules. Proc. natn. Acad. Sci. U.S.A. 80, 6019-6023.

Matzinger P. and Bevan M. J. (1977) Hypothesis: why do so many lymphocytes respond to major histocompatibility antigens? Cell. Immun. 29, 1-5.

Melief C. J. M., DeWaal L. P., van der Meulen M. Y.,
Melvold R. M. and Kohn H. I. (1980) Fine specificity of alloimmune cytotoxic $T$-lymphocytes directed against $\mathrm{H}$ $2 \mathrm{~K}$. A study with $\mathrm{K}^{\mathrm{b}}$ mutants. J. exp. Med. 151, 993-1013

Miller J. F. A. P. Vadas M. A., Whitelaw A. and Gamble J. (1975) H-2 gene complex restricts transfer of delayed-type hypersensitivity in mice. Proc. natn. Acad. Sci. U.S.A. 72, 5095-5098.

Molnar-Kimber K. and Sprent J. (1983) Absence of H-2 restriction in primary and secondary mixed-lymphocyte reactions to strong Mls determinants. J. exp. Med. 151, 407-417.

Murphy D. B. and Shreffler D. C. (1975) Cross-reactivity between $\mathrm{H}-2 \mathrm{~K}$ and $\mathrm{H}-2 \mathrm{D}$ products. I. Evidence for extensive and reciprocal cross-reactivity. J. exp. Med. 141, 374-391.

Nagy Z. and Elliot B. E. (1979) The receptor specificity of alloreactive $T$ cells. Distinction between stimulator K. I and $\mathrm{D}$ region products and degeneracy of third party $\mathrm{H}-2$ recognition by low affinity T cells. J. exp. Med. 150 , 1520-1537.

Nakayama E., Shiku H., Stockert E., Oettgen H. F. and Old L. J. (1979) Cytotoxic T cells: Lyt phenotype and blocking of killing activity by Lyt antisera. Proc. natn. Acad. Sci. U.S.A. 76, 1977-1981.

Ohno S., Matsunaga T., Epplen J. T., Itakura K. and Wallace R. B. (1982) Identification of the 45-base-long primordial building block of the entire class I major histocompatibility complex gene. Proc. natn. Acad. Sci. U.S.A. 79, 6342-6346.

Quill H. and Schwartz B. D. (1984) Subunit structure of guinea pig Ia.1 antigens. J. Immun. 132, 197-302.

Rao A., Fass S. J. and Cantor H. (1984) Activation specificity of arsonate-reactive $T$ cell clones. Structural requirements for hapten recognition and comparison with monoclonal antibodies. J. exp. Med. 159, 479-494.

Reinherz E. L., Meuer S. C. and Schlossman S. F. (1983) The delineation of antigen receptors on human $\mathrm{T}$. lymphocytes. Immun. Today 4, 5-8.

Rosenthal A. S. and Shevach E. M. (1973) Function of macrophages in antigen recognition by guinea pig lymphocytes. I. Requirement for histocompatible macrophages and lymphocytes. J. exp. Med. 138, 1194-1212.

Schrader J. W. (1979) Nature of T-cell receptor. Scand. J. Immun. 10, 387-393.

Sherman L. A. (1982) Recognition of conformational determinants on $\mathrm{H}-2$ by cytolytic T-lymphocytes. Nature, Lond. 297, 511-513.

Shinohara N. and Sachs D. H. (1979) Mouse alloantibodies capable of blocking cytotoxic T-cell function. I. Relationship between the antigen reaction with blocking antibodies and the Lyt-2 locus. J. exp. Med. 150, 432-444.

Silverstein A. M. and Gell P. G. H. (1962) Delayed hypersensitivity to hapten-protein conjugates. II. Antihapten specificity and heterogeneity of the delayed response. J. exp. Med. 115, 1053-1064.

Simpson E., Mobraaten L., Chandler P., Hetherington C. Hurme C., Brunner C. and Bailey D. (1978) Crossreactive cytotoxic responsives. $\mathrm{H}-2$ restricted are more specific than anti-H-2 responses. J. exp. Med. 148, $1478-1487$.

Steinmetz M. and Hood L. (1983) Genes of the major histocompatibility complex in mouse and man. Science 222, 727-733.

Stockinger H., Bartlett R., Pfizenmaier K., Rollinghoff M. and Wagner H. (1981) H-2 restriction as a consequence of intentional priming. Frequency analysis of alloantigen-restricted, trinitrophenyl-specific cytotoxic $T$ lymphocyte precursors within thymocytes of normal mice. J. exp. Med. 153, 1629-1639.

Swain S. L., Dialynas D. P., Fitch F. W. and English M. 
(1984) Monoclonal antibody to L3T4 blocks the function of Class 2 major histocompatibility complex antigens. $J$. Immun. 132, 1118-1123.

Swain S. L., Dutton R. W., Schwab R. and Yamamoto J. (1983) Xenogeneic human anti-mouse T cell responses are due to the activity of the same functional $T$ cell subsets responsible for allospecific and major histocompatibility complex-restricted responses. J. exp. Med. 157, 720-729.

Thelander L. and Reichard P. (1979) Reduction of ribonucleotides. A. Rev. Biochem. 48, 133-158.

Townsend A. R. M., Taylor P. M., Melief C. J. M. and Askonas B. A. (1983a) Recognition of $D^{b}$ and $K^{b}$ gene products by influenza-specific cytotoxic $\mathrm{T}$ cells. Immunogenetics 17, 283-294.

Townsend A. R. M., Taylor P. M., Melief C. J. M. and Askonas B. A. (1983b) Diversity in the interaction of influenza-A-specific cytotoxic $\mathrm{T}$ cells with $\mathrm{H}-2 \mathbf{K}^{\mathrm{b}}$ mutant targets. Immunogenetics 17, 543-549.

Triebel F., Missenard-Leblond V., Couty M.-C., Charron D. J. and Debre P. (1984) Differential inhibition of human antigen-specific $T$ cell clone proliferative re sponses by distinct monoclonal anti-HLA-DR antibodies. J. Immun. 132, 1773-1778.

von Boehmer H., Hengartner H., Nabholz M., Lenhardt W., Schreier M. H. and Haas W. (1979) Fine specificity of a continuously growing killer cell clone specific for $\mathrm{H}$ Y antigen. Eur. J. Immun. 9, 592-597.

Vucak I., Juretic A., Nagy Z. A. and Klein J. (1982) Cytolytic $\mathrm{T}$ cells activated by $\mathrm{H}-2$ controlled E-molecules cross-react with A-molecules. Immunogenetics $15,519-527$.

Wall K. A., Lorber M. I., Lolan M. R., McClatchey S. and Fitch F. W. (1983) Inhibition of proliferation of Mls- and Ia-reactive cloned T-cells by a monoclonal antibody against a determinant shared by I-A and I-E. $J$. Immun. 131, 1056-1064.

Webb S. R., Molnar-Kimber K., Bruce J., Sprent J. and Wilson D. B. (1981) T cell clones with dual specificity for Mls and various major histocompatibility complex determinants. J. exp. Med. 154, 1970-1974.

Whitmore A. C. and Gooding L. R. (1981) Specificities of killing by $\mathrm{T}$-lymphocytes generated against syngeneic SV40 transformants: cross-reactivity of the $\mathrm{H}-2 \mathrm{~K}^{\mathrm{bm}}$ through $\mathrm{K}^{\mathrm{bm} 4} \mathrm{H}-2$ mutant alleles in $\mathrm{K}^{\mathrm{b}}$-restricted SV40 specific killing. J. Immun. 127, 1207-1211.

Williamson A. R. (1980) Three-receptor clonal expansion model for selection of self-recognition in the thymus. Nature, Lond. 283, 527-532.

Wilson B. S., Glassy M. C., Quarenta V., Ng A.-K. and Ferrone S. (1981) Effect of tunicamycin on the assembly and antigenicity of HLA antigens: analysis with monoclonal antibodies. Scand. J. Immun. 14, 201-205.

Wilson D. B., Fischer-Lindahl K., Wilson D. H. and Sprent J. (1977) The generation of killer cells to trinitrophenyl-modificd allogeneic targets by lymphocyte populations negatively selected to strong alloantigens. J. exp. Med. 146, 361-367.

Zinkernagel R. M. (1976) H-2 compatibility requirement for virus-specific $T$ cell-mediated cytolysis. The $\mathrm{H}-2 \mathrm{~K}$ structure involved is encoded by a single cistron defined by $\mathrm{H}-2 \mathrm{~K}^{\mathrm{b}}$ mutant mice. J. exp. Med. 143, 437-443.

Zinkernagel R. M. and Doherty P. C. (1974a) Restriction of in vitro $\mathrm{T}$ cell-mediated cytotoxicity in lymphocytic choriomeningitis within a syngeneic or semi-allogeneic system. Nature, Lond. 248, 701-702.

Zinkernagel R. M. and Doherty P. C. (1974b) Immunological surveillance against altered self components by sensitized $T$ lymphocytes in lymphocytic choriomeningitis. Nature, Lond. 251, 547-548.

Zinkernagel R. M. and Rosenthal K. L. (1981) Experiments and speculation on antiviral specificity of $T$ and $B$ cells. Immun. Rev. 58, 131-155.

\section{NOTE ADDED IN PROOF}

After submission of this paper, it came to our attention that R. H. Schwartz and coworkers have also considered an allosteric model as a result of their studies of T-cells specific for cytochrome $c$ fragments [Schwartz R. H., Heber-Katz E. and Hansburg D. (1983) In Intercellular Communication in Leucocyte Function (Edited by Parker J. W. and O'Brien R. L.), pp. 117-125. John Wiley, New York].

Recent progress in cloning T-cell receptor genes [Saito et al. (1984) Nature, Lond. 309, 757-762] has led to the preliminary conclusion that the T-cell receptor is structurally analogous to an immunoglobulin light-chain dimer. If the $\alpha$ - and $\beta$-chains of the T-cell receptor are weakly associated, as is the case for light-chain dimers, then binding site structures dependent on the relative positions of $V_{\alpha}$-and $V_{\beta}$-domains should be flexible, as required for our model. 